\title{
Brachial Plexus Anaesthesia: A Comparative Study on Supraclavicular Subclavian Perivascular Technique with the Axillary Transarterial Technique with A Tourniquet
}

\section{Mohammad Harun Or Roshid ${ }^{1 *}$ \\ Mohammad Sharif ${ }^{2}$ \\ Md Nizam Uddin \\ Sheikh Rukun Uddin Ahmed ${ }^{3}$ \\ Shamim Ara Begum ${ }^{4}$ \\ Pronoy Kumar Datta' \\ A K M Shamsul Alam}

${ }^{1}$ Department of Anesthesiology \& Intensive Care Medicine Chittagong Medical College

Chittagong, Bangladesh.

${ }^{2}$ Director (MCH Service)

Directorate General of Family Planning, Bangladesh

${ }^{3}$ Consultant Anaesthesiologist \&

Deputy Director of Family Planning, Chittagong, Bangladesh.

${ }^{4}$ Department of Obstretics \& Gynaecology University of Science \& Technology Chittagong (USTC) Chittagong, Bangladesh.

*Correspondence to:

Dr. Mohammad Harun Or Roshid Assistant Professor

Department of Anesthesiology \& Intensive Care Medicine Chittagong Medical College

Chittagong, Bangladesh.

Mobile : +8801817 706725

Email : harun11a@yahoo.com

www.banglajol.info/index.php/CMOSHMCJ

\begin{abstract}
Objectives : To make a comparative evaluation of efficacy of brachial plexus blockade between supraclavicular subclavian perivascular technique and axillary transarterial technique with a tourniquet and also to compare the latency \& potency of the block, to ascertain the risks of complications between the techniques and to compare the haemodynamic stability of the patient. Methods : For this purpose a total of 100 undergoing surgery for distal to the midarm. They were randomly selected by odd and even numbering method. These patients were divided into two groups (Group A: subclavian perivascular supraclavicular technique bearing all the odds numbers and Group B: transarterial axillary technique with a tourniquet bearing all the even numbers; fifty patients in each group. Results : The only exception is the mean on set time of sensory block was $11.0 \pm 2.6$ minutes and $14.3 \pm 2.1$ minutes in Group A and Group B respectively. The mean on set time of motor block were 18.3 \pm 3.9 minutes in Group A and 21.4 \pm 3.2 minutes in Group B. So the mean on set time of sensory block and motor block were statistically significant $(p<0.05)$. Most of the patients found complete sensory block and complete motor block between two groups and no significant $(\mathrm{p}>0.05)$ difference was found in the present study. Adequate efficacy of block were predominate in both groups and no significant ( $>0.05$ ) difference was found. The level of satisfaction of surgeon and it was found that $92.0 \%$ in Group A and $94.0 \%$ in Group B were satisfied. Patient's co-operation was found $92.0 \%$ and $94.0 \%$ in Group A and Group B respectively. No significant $(p>0.05)$ difference were found in terms of surgeon satisfaction and patients cooperation between two groups. Conclusion : It can be concluded that the supraclavicular subclavian perivascular technique and axillary transarterial technique with a tourniquet both are equally effective and safe method for providing brachial plexus block distal to midarm (Lower half of the arm, elbow, forearm and hand).
\end{abstract}

Key words : Brachial plexus blockade; Supraclavicular subclavian perivascular technique; Axillary transarterial technique.

\section{INTRODUCTION}

Brachial plexus blockade is gaining popularity day by day for the upper extremity surgery because it lends a lot of advantages over general anesthesia ${ }^{1,2}$.

The present study on brachial plexus anaesthesia : A comparative study on supraclavicular Subclavian Perivascular Technique (SCB) with the axillary transarterial technique with a tourniquet.These two approaches were first conducted by Brand et al. at a time when Axillary Blockade (AXB) was gaining favour as an efficacious approach without risk of pneumothorax. The authors showed that AXB provides successful anaesthesia significantly more often than SCB (92\% vs. $84 \%)^{3}$. Thompson et al. found no significant difference in block success between SCB $(83 \%)$ and $\mathrm{AXB}(85 \%)$ in a similarly nonrandomized and retrospective study of 1913 surgeries ${ }^{4}$. 
Among the supraclavicular approaches to the brachial plexus block, the subclavian perivascular approach is well establishing method of anaesthesia for the upper extremity ${ }^{5}$. All blocks were performed according to Winnie's technique, eliciting a paresthesia was mandatory ${ }^{6,7}$. Supraclavicular subclavian perivascular block usually has a very faster onset; a preliminary test for onset of anaesthesia was performed within 5 minutes of the injection. Time of onset of paresis and time of onset of motor block is shorter in supraclavicular perivascular technique. It is safe and effective ${ }^{8}$.

The transarterial technique has been associated with high rate of successful anaesthesia for AXB (88\% vs. $84 \%)$ in two large retrospective studies 9 . The transarterial technique has been refined by Hickey et al. They found no difference in overall success rate of injection in front, behind and injection of half the dose in front and half behind the artery. Rather the efficacy of AXB can be enhanced to greater extent by applying a digital pressure distal to the site of injection and application of a tourniquet ${ }^{7}$.

The choices of local anesthetic agents for brachial plexus block are $20 \mathrm{ml}$ of $1.5 \%$ lignocaine with adrenaline $(1: 200000)$ and $20 \mathrm{ml}$ of $.25 \%$ bupivacaine, a total of $40 \mathrm{ml}$ from the both sides for rapid onset and long duration ${ }^{10}$. The maximum safest dose of lignocaine with adrenaline is $7 \mathrm{mg} / \mathrm{kg} \mathrm{BW}$ and that of bupivacaine is $2.5 \mathrm{mg} / \mathrm{kg} \mathrm{BW}^{11}$. Onset of action of lignocaine is 5-7 mins, duration is 2-4 hrs, potency is moderate and toxicity is also moderate (CNS) but for bupivacaine, onset time is $10-15$ mins, duration is 6-12 hrs, potency is high and toxicity is also high (CVS). The choice of the L/A must be taken into the considerations of the duration of the surgery, regional techniques used, surgical requirements, the potential for local or systemic toxicities ${ }^{11}$.

\section{MATERIALS \& METHODS}

This prospective comparative randomized clinical trial was carried out in in the Department Anesthesiology in Chittagong Medical College Hospital $(\mathrm{CMCH})$ in collaboration with the Departments of General Surgery, Casualty and Orthopedic Surgery over a period of 1 year from July, 2007 to June, 2008.

A total of 100 undergoing surgery for distal to the midarm. They were randomly selected by odd and even numbering method. These patients were divided into two groups (Group A: subclavian perivascular supraclavicular technique bearing all the odds numbers and Group B: transarterial axillary technique with a tourniquet bearing all the even numbers; fifty patients in each group.

On the day of operation, Group-A patient were identified and taken to the OT. Baselines reading of pulse, BP, SPaO2, RR were recorded on the case record form on the OT table. Intravenous channels were opened with an intravenous cannula of 18-G size in the contralateral upper extremity. Preoperative medication was done by Injection midazolam .1 mg/kg i/v just before insertion of block to keep the patient cool and calm. The patients were lie supine position without a pillow, with head turned opposite to the side to be blocked.
The subclavian artery pulse was palpated $1.5-2.0 \mathrm{~cm}$ posterior to the midpoint of the clavicle. The subclavian artery was used as a landmark. From this point, after appropriate preparation and injection of a skin wheal, the needle and syringe (21-G, 4.0 $\mathrm{cm}$ long) was inserted cephalated to this point and was directed caudally until a paresthesia is elicited oand the $1^{\text {st }}$ rib is encountered. Then keeping the needle in situ the local anesthetic was inserted from syringes ${ }^{2,12}$. At that time another recording of pulse, $\mathrm{BP}, \mathrm{SPaO}_{2}$ and $\mathrm{RR}$ was taken. Sensory block was evaluated by pinprick for all 4 terminal nerves (Musculocuteneous, radial, median and ulnar nerves), whereas the motor block was assessed by asking the patient to flex the fore-arm and hand against gravity. Onset of sensory block was defined as the time elapsed between the injection of drugs and complete loss of pinprick perception of the hand, while onset of motor block was defined as the time elapsed from injection of drugs to the starting of motor block. Onset time of sensory and motor block, duration of surgery was recorded. Efficacy may be termed as the achievement of adequate surgical anaesthesia to perform a surgery. Efficacy may be adequate or inadequate. Adequate surgical anaesthesia means the ability to proceed surgery without supplementation of additional local or general anaesthesia ${ }^{5}$. Any adjuvant like, pethidine, fentanyl, diazepam, midazolam or any other analgesics or GA if needed was noted. Any complications will be cited like LA toxicities, intravascular injection, pneumothorax, haematoma formation, Abscess formation, Tourniquet pain, phrenic nerve block, respiratory distress or any others was noted by yes/no. If respiratory distress occurs, phrenic nerve block and pneumothorax was excluded by X-ray chest PA view. Surgeon's satisfaction and patient's co-operation was also be recorded. Surgon's satisfaction was noted as satisfied (Yes)/ dissatisfied (No) and patient co-operation will be noted as co-opertive and noncooperative. Per operative reading of pulse, $\mathrm{BP}, \mathrm{SPaO} 2$, RR was recorded for 0 - just after injection, 1-3-every 10 minutes interval for 30 minutes after " 0 ", 4 \& onwards- every 15 minutes interval till the end of the surgery.

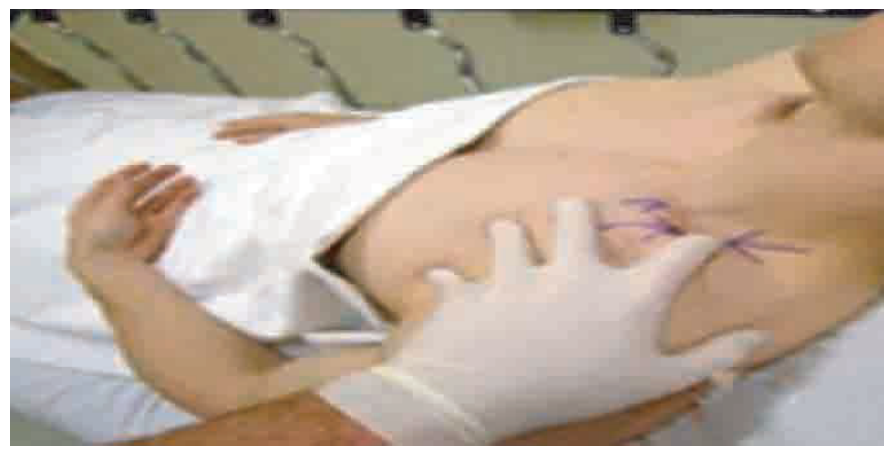

Figure 1: Supraclavicular brachial plexus block 
For the patient's of Group B, patient's preparation, preoperative assessment and baseline reading was same as Group A. The patient was supine position with the head facing away from the side to be blocked. The arm was abducted 90 degree at the shoulder, externally rotated and flexed at the elbow. A tourniquet will be applied to the upper arm just below the axilla. The axillary artery will be palpated at the most proximal location in the axilla. Once the pulse will be felt, it should be straddled between the index and middle finger and firmly pressed against the humerous to prevent rolling of the axillary artery during the block performance. As axillary artery was taken as an anatomical landmark, the block will be performed with a relatively sharp needle $(23 \mathrm{G}, 2.5 \mathrm{~cm} \mathrm{long})^{2,12}$. The reading of pulse, $\mathrm{BP}, \mathrm{SPaO}_{2}, \mathrm{RR}$ was recorded on the data sheet as before. Assessment of sensory and motor block, Onset of sensory and motor block, onset time of surgery, duration of surgery and duration of block was recorded.

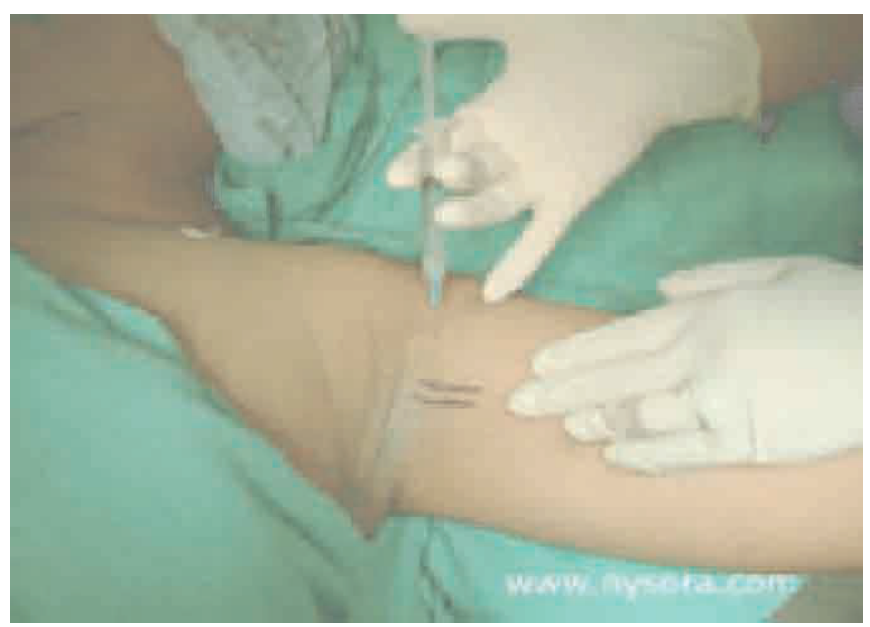

Figure 2 : Axillary block

\section{RESULTS}

Table I : Demographic characteristics \& Sex distribution of the patients $(n=100)$

\begin{tabular}{|c|c|c|c|c|c|}
\hline & $\begin{array}{l}\text { Group A } \\
(n=50) \\
\text { Mean } \pm \text { SD }\end{array}$ & $\begin{array}{l}\text { Group B } \\
(\mathrm{n}=50) \\
\text { Mean } \pm \text { SD }\end{array}$ & t value & df & p value \\
\hline $\begin{array}{l}\text { Age (years } \\
\text { Range (min-max) }\end{array}$ & $\begin{array}{l}35.9 \pm 13.1 \\
(19-70)\end{array}$ & $\begin{array}{l}37.4 \pm 12.3 \\
(20-70)\end{array}$ & 0.59 & 98 & $0.556^{\mathrm{NS}}$ \\
\hline $\begin{array}{l}\text { Weight }(\mathrm{Kg}) \\
\text { Range (min-max) }\end{array}$ & $\begin{array}{l}55.3 \pm 6.4 \\
(45-70)\end{array}$ & $\begin{array}{l}57.3 \pm 6.4 \\
(45-70)\end{array}$ & 1.56 & 98 & $0.122^{\mathrm{NS}}$ \\
\hline Sex & $\begin{array}{l}\text { Group A } \\
(\mathrm{n}=50) \\
\text { No. } \%\end{array}$ & $\begin{array}{l}\text { Group B } \\
(\mathrm{n}=50) \\
\text { No. } \%\end{array}$ & $\begin{array}{l}\chi^{2} \\
\text { value }\end{array}$ & $\mathrm{df}$ & $\mathrm{p}$ value \\
\hline $\begin{array}{l}\text { Male } \\
\text { Female }\end{array}$ & $\begin{array}{ll}25 & 50.0 \\
25 & 50.0\end{array}$ & $\begin{array}{ll}34 & 68.0 \\
16 & 32.0\end{array}$ & 3.35 & 1 & $0.067^{\mathrm{NS}}$ \\
\hline
\end{tabular}

Group A= Subclavian perivascular supraclavicular technique Group $B=$ Transarterial axillary technique with a tourniquet $\mathrm{Ns}=$ Not significant

$\mathrm{P}$ value reached from Chi square test
No significant mean age and weight differences were found between two groups in unpaired " $t$ " test (Table 1). In case of sex difference was not statistically significant $(p>0.05)$ in chi square test (Table 1).

Table 2 : Onset time of sensory \& motor block and Status of sensory \& motor block between two groups $(n=100)$

\begin{tabular}{|c|c|c|c|c|c|}
\hline & $\begin{array}{l}\text { Group A } \\
(\mathrm{n}=\mathbf{5 0}) \\
\text { Mean } \pm \text { SD }\end{array}$ & $\begin{array}{l}\text { Group B } \\
(\mathrm{n}=\mathbf{5 0}) \\
\text { Mean } \pm \text { SD }\end{array}$ & $\begin{array}{c}\mathrm{t} \\
\text { value }\end{array}$ & df & $\begin{array}{c}\mathrm{p} \\
\text { value }\end{array}$ \\
\hline $\begin{array}{l}\text { Onset time of sensory } \\
\text { block (min) } \\
\text { Range (min-max) }\end{array}$ & $\begin{array}{l}11.0 \pm 2.6 \\
(7-20)\end{array}$ & $\begin{array}{l}14.3 \pm 2.1 \\
(10-20)\end{array}$ & 6.76 & 98 & $0.001^{\mathrm{S}}$ \\
\hline $\begin{array}{l}\text { Onset of motor block } \\
\text { Range (min-max) }\end{array}$ & $\begin{array}{l}18.3 \pm 3.9 \\
(12-30)\end{array}$ & $\begin{array}{l}21.4 \pm 3.2 \\
(15-30)\end{array}$ & 4.32 & 98 & $0.001^{\mathrm{S}}$ \\
\hline Sensory block & $\begin{array}{l}\text { Group A } \\
(\mathrm{n}=50) \\
\text { No. } \%\end{array}$ & $\begin{array}{l}\text { Group B } \\
(\mathrm{n}=50) \\
\text { No. } \%\end{array}$ & $\begin{array}{c}\chi^{2} \\
\text { value }\end{array}$ & $\mathrm{df}$ & $\mathrm{p}$ value \\
\hline $\begin{array}{l}\text { Complete } \\
\text { Incomplete }\end{array}$ & $\begin{array}{ll}46 & 92.0 \\
4 & 8.0\end{array}$ & $\begin{array}{ll}47 & 94.0 \\
3 & 6.0\end{array}$ & 0.15 & 1 & $0.500^{\mathrm{NS}}$ \\
\hline Motor block & $\begin{array}{l}\text { Group A } \\
(\mathrm{n}=50) \\
\text { No. } \%\end{array}$ & $\begin{array}{l}\text { Group B } \\
(\mathrm{n}=50) \\
\text { No. } \%\end{array}$ & $\chi^{2}$ & value & df \\
\hline $\begin{array}{l}\text { Complete } \\
\text { Incomplete }\end{array}$ & $\begin{array}{ll}46 & 92.0 \\
4 & 8.0\end{array}$ & $\begin{array}{ll}47 & 94.0 \\
3 & 6.0\end{array}$ & 0.15 & 1 & $0.500^{\mathrm{NS}}$ \\
\hline
\end{tabular}

Group $A=$ Subclavian perivascular supraclavicular technique

Group B= Transarterial axillary technique with a tourniquet

$\mathrm{S}=$ Significant

$P$ value reached from unpaired t-test \& Fisher exact test

The mean onset time of sensory block were $11.0 \pm 2.6$ minutes and 14.3 \pm 2.1 minutes in Group A and Group B respectively. The mean onset times of motor block between two groups were 18.3 \pm 3.9 minutes and 21.4 \pm 3.2 minutes in Group A and Group $\mathrm{B}$ respectively. The comparison between two groups showed highly significant $(\mathrm{p}<0.001)$ in unpaired ' $\mathrm{t}$ ' test. Most of the patients found complete sensory block between two groups and no significant $(\mathrm{p}>0.05)$ difference was found between two groups in Fisher exact test. Majority of the patients found complete motor block in both groups and no significant $(\mathrm{p}>0.05)$ difference was found between two groups in Fisher exact test (Table 2).

Table 3 : Type of adjuvant required between two groups $(n=100)$

\begin{tabular}{llllllll}
$\begin{array}{l}\text { Adjuvant } \\
\text { needed }\end{array}$ & \multicolumn{2}{c}{$\begin{array}{c}\text { Group A } \\
(\mathrm{n}=\mathbf{5 0})\end{array}$} & \multicolumn{2}{c}{$\begin{array}{c}\text { Group B } \\
(\mathrm{n}=\mathbf{5 0})\end{array}$} & $\chi^{\mathbf{2}}$ value & df & p value \\
& No. & $\%$ & No. & $\%$ & & & \\
Fentanyl & 2 & 4.0 & 4 & 8.0 & 3.82 & 4 & 0.430 NS \\
Pethidine & 20 & 40.0 & 15 & 30.0 & & & \\
Midazolam & 18 & 36.0 & 20 & 40.0 & & & \\
Diazepam & 4 & 8.0 & 8 & 16.0 & & & \\
None & 6 & 12.0 & 3 & 6.0 & & &
\end{tabular}

Group A= Subclavian perivascular supraclavicular technique Group B= Transarterial axillary technique with a tourniquet $\mathrm{Ns}=$ Not significant

$\mathrm{P}$ value reached from Chi square test 
The above table shows the type of position of adjuvant received by the patients during surgery and found $2(4.0 \%)$ received fentanyl, 20(40.0\%) pethidine, $18(36.0 \%)$ midazolam and 4(8.0\%) diazepam in Group A. whereas in Group B, 4(8.0\%) received fentanyl, 15(30.0\%) pethidine, 20(40.0\%) midazolam and $8(16.0 \%)$ diazepam. No adjuvant received 6(12.0\%) and $3(6.0 \%)$ in Group A and Group B respectively. No significant $(p>0.05)$ difference was found in terms of type of adjuvant received between two groups in chi square test (Table 3 ).

Table 4 : Status of G/A and Duration of surgery between two groups $(\mathrm{n}=100)$

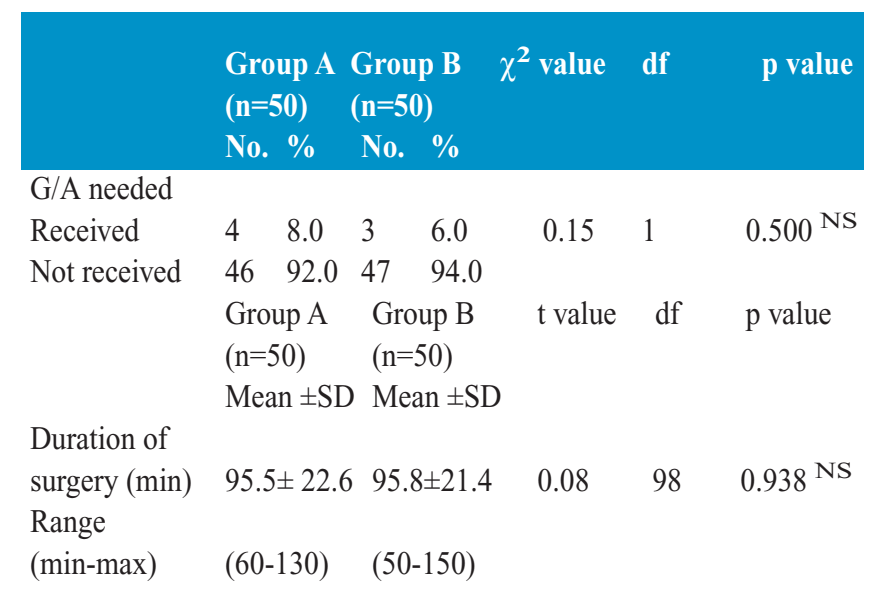

Group $A=$ Subclavian perivascular supraclavicular technique Group $\mathrm{B}=$ Transarterial axillary technique with a tourniquet $\mathrm{Ns}=$ Not significant

$P$ value reached from Fisher exact test \& unpaired t-test

Only $4(8.0 \%)$ and $3(6.0 \%)$ received G/A between Group A and Group B respectively. No significant $(\mathrm{p}>0.05)$ difference was found between two groups in Fisher exact test. The mean $( \pm \mathrm{SD})$ duration of surgery was $95.5 \pm 22.6$ minutes in Group A and $95.8 \pm 21.4$ minutes in Group B. The comparison between two groups showed no significant $(p>0.05)$ difference in unpaired "t" test (Table 4).

Table 5 : Distribution of complications of the patients $(n=100)$

\begin{tabular}{llllllll} 
& \multicolumn{2}{l}{$\begin{array}{l}\text { Group A } \\
(\mathbf{n}=\mathbf{5 0})\end{array}$} & $\begin{array}{l}\text { Group B } \\
(\mathrm{n}=\mathbf{5 0})\end{array}$ & $\begin{array}{c}\chi^{\mathbf{2}} \\
\text { value }\end{array}$ & df & p value \\
& No. & $\%$ & No. & $\%$ & & & \\
No complications & 41 & 82.0 & 45 & 90.0 & & & \\
Complications & & & & & & & \\
Phrenic nerve block & 0 & 0.0 & 0 & 0.0 & - & - & - \\
Respiratory distress & 5 & 10.0 & 2 & 4.0 & 0.61 & 1 & $0.218^{\mathrm{NS}}$ \\
Haematoma & 4 & 8.0 & 3 & 6.0 & 0.00 & 1 & $0.500^{\mathrm{NS}}$ \\
Pneumothorax & 0 & 0.0 & 0 & 0.0 & - & - & - \\
Abscess formation & 0 & 0.0 & 0 & 0.0 & & & \\
Tourniquet pain & 0 & 0.0 & 2 & 4.0 & 0.51 & 1 & 0.247 NS \\
Hypersensitivity & 0 & 0.0 & 0 & 0.0 & & & \\
CNS & 0 & 0.0 & 0 & 0.0 & & & \\
CVS & 0 & 0.0 & 0 & 0.0 & & & \\
\hline
\end{tabular}

Group $A=$ Subclavian perivascular supraclavicular technique Group $B=$ Transarterial axillary technique with a tourniquet $\mathrm{S}=$ Significant

Ns $=$ Not significant

$\mathrm{P}$ value reached from Fisher exact test

The above table shows the complications of the patients and found 5(10.0\%) respiratory distress in Group A and 2(4.0\%) in Group B. Haematoma was 4(8.0\%) in Group A and 3(6.0\%) in Group B. Tourniquet pain only observed 2(4.0\%) in group B. Others complications like pneumothorax, abscess formation, tourniquet pain, hypersensitivity, CNS and CVS was not found between two groups. No significant $(p>0.05)$ difference were found in terms of complications between two groups in Fisher exact test (Table 5).

Table 6 : Per operative monitoring of systolic blood pressure $(n=100)$

\begin{tabular}{llllll}
$\begin{array}{l}\text { Systolic blood } \\
\text { pressure }\end{array}$ & $\begin{array}{l}\text { Group A } \\
(\mathrm{n}=50) \\
\text { Mean } \pm \text { SD }\end{array}$ & $\begin{array}{l}\text { Group B } \\
(\mathrm{n}=50) \\
\text { Mean } \pm \text { SD }\end{array}$ & t value & df & p value \\
Baseline & $119.5 \pm 11.1$ & $119.6 \pm 10.2$ & 0.04 & 98 & $0.969^{\mathrm{NS}}$ \\
Just after injection & $120.2 \pm 12.0$ & $120.3 \pm 10.5$ & -0.049 & 98 & $0.961^{\mathrm{NS}}$ \\
After 60 min & $120.6 \pm 11.5$ & $120.2 \pm 11.1$ & 0.165 & 98 & $0.869^{\mathrm{NS}}$ \\
After 120 min & $120.2 \pm 12.4$ & $117.0 \pm 12.8$ & 1.266 & 98 & $0.209^{\mathrm{NS}}$ \\
End of operation & $122.4 \pm 12.2$ & $119.3 \pm 12.6$ & 1.284 & 98 & $0.202^{\mathrm{NS}}$ \\
Diastolic blood & Group A & Group B & t value & df & p value \\
pressure & $(\mathrm{n}=50)$ & $(\mathrm{n}=50)$ & & & \\
& Mean $\pm \mathrm{SD}$ & Mean $\pm \mathrm{SD}$ & & & \\
Baseline & $75.1 \pm 7.5$ & $76.0 \pm 6.5$ & 0.62 & 98 & $0.539^{\mathrm{NS}}$ \\
Just after injection & $74.2 \pm 9.4$ & $75.6 \pm 9.0$ & 0.719 & 98 & $0.474^{\mathrm{NS}}$ \\
After 60 min & $76.8 \pm 9.2$ & $74.5 \pm 8.9$ & -0.485 & 98 & $0.629^{\mathrm{NS}}$ \\
After 120 min & $76.4 \pm 8.7$ & $75.4 \pm 9.0$ & 0.114 & 98 & $0.910^{\mathrm{NS}}$ \\
End of operation & $73.6 \pm 8.5$ & $71.4 \pm 8.9$ & -1.235 & 98 & $0.220^{\mathrm{NS}}$ \\
\hline
\end{tabular}

Group $A=$ Subclavian perivascular supraclavicular technique Group $\mathrm{B}=$ Transarterial axillary technique with a tourniquet $\mathrm{Ns}=$ Not significant

$P$ value reached from unpaired t-test

The table 6 showed per-operative mean systolic blood pressure changes at different times and found no significant $(\mathrm{p}>0.05)$ difference between two groups. Per-operative mean diastolic blood pressure changes at different times and found no significant $(p>0.05)$ difference between two groups.

\section{DISCUSSION}

In the present study it was observed that diagnosis, proposed opn and co-existing disease were almost similar between two groups. No significant $(p>0.05)$ difference were found between Group A and Group B.

Shrestha et al have observed in their study on 40 patients in two groups, the mean age was $33.2 \pm 9.29$ years in bupivacaine and $33.65 \pm 9.34$ years in bupivacaine with midazolam groups. 
The mean $( \pm \mathrm{SD})$ weight were $60.0 \pm 5.3 \mathrm{~kg}$ and $58.1 \pm 5.2 \mathrm{~kg}$ between two groups. Another study on 60 patients and divided in to two groups, one groups received Tramadol $(2 \mathrm{mg} / \mathrm{kg})$ and the other group received Dexamethasone $(8 \mathrm{mg})$ as an admixture to Bupivacaine. They observed that the mean age of the patients were $39.60 \pm 13.36$ and $36.27 \pm 15.01$ years between two groups. The mean weight were $58.17 \pm 6.53$ and $56.40 \pm 7.20$ $\mathrm{kg}$ in Group I and Group II respectively, which is consistent with the present study findings ${ }^{14}$. Carlo et al (2000) showed mean age was $36.2 \pm 13.8$ years and mean weight was $77.8 \pm 16.9$ $\mathrm{kg}$, mean weight was higher but mean age was consistent with the present study. Regarding the sex incidence in the present study male female ratio was $1.4: 1$, which is closely resemble with Sia et al. and Shrestha et al. findings, where they found male female ratio was $1.5: 1$ and 1.4:1 respectively. Jarbo et al. have observed in their study that male female ratio was $2.3: 1$, which is higher with the present study. In this study male was $50.0 \%$ in Group A and $68.0 \%$ in Group B, no statistically significant $(p>0.05)$ difference was observed in terms of sex difference between two groups ${ }^{13,14}$.

Shrestha et al. observed the mean onset time of sensory block were $20 \pm 3.8$ minutes and $12 \pm 2.9$ minutes in bupivacaine and group bupivacaine with midazolam group respectively. The mean onset time of motor block were $17.1 \pm 3.83$ minutes and $9.2 \pm 2.38$ minutes in bupivacaine and group bupivacaine with midazolam group respectively. Shrestha et al. also reported the mean onset time of sensory block were $18.47 \pm 2.03$ minutes and $16.76 \pm 2.34$ minutes in Group I and Group II respectively. The mean onset time of motor block were $13.93 \pm 1.66$ minutes and $12.90 \pm 1.49$ minutes in Group I and Group II respectively, which were significantly differ between two groups. In the current study the mean onset time of sensory block and motor block were significantly $(\mathrm{p}<0.05)$ higher in Group B with compared to Group A, where the mean onset time of sensory block was 11.0 \pm 2.6 minutes and $14.3 \pm 2.1$ minutes in Group A and Group B respectively. The mean onset time of motor block were 18.3 \pm 3.9 minutes in Group A and $21.4 \pm 3.2$ minutes in Group B, which is comparable with the above mentioned study $^{14}$

Most (46 in Group A and 47 in Group B) of the patients found complete sensory block and complete motor block between two groups and no significant $(\mathrm{p}>0.05)$ difference was found in the present study. Sia et al found complete motor block 30 and satisfactory motor block 17 in paresthesia group and in peripheral stimulation group complete motor block 37 and satisfactory motor block 12 which support the present study. The result of the present study obtained is higher than the above study ${ }^{13}$.

In the current study it was found that $4.0 \%$ received fentanyl, $40.0 \%$ pethedine, $30.0 \%$ midazolam and $8.0 \%$ diazepam in group A; whereas in group B, $8.0 \%$ received fentanyl, 30.0\% pethidine, $40.0 \%$ midazolam and $16.0 \%$ diazepam. No adjuvant received $12.0 \%$ and $6.0 \%$ in group A and group B respectively. No significant $(\mathrm{p}>0.05)$ difference was found in terms of type of adjuvant received between two groups.
Only $8.0 \%$ and $6.0 \%$ received G/A between Group A and Group B respectively in the current study. No significant $(p>0.05)$ difference was found between two groups. Andersson et al. showed conversion to general anaesthesia was required in 23 patients (12\% of anaesthetic records) and in 18 patients $(10 \%)$ this was because regional anaesthesia was said to be inadequate, which is higher with the present study ${ }^{15}$.

In the present series the mean duration of surgery was almost similar between two groups and no significant $(p>0.05)$ difference was found between two groups in terms of duration of surgery in the current study. The mean $( \pm \mathrm{SD})$ duration of surgery was $95.5 \pm 22.6$ minutes in Group A and 95.8 \pm 21.4 minutes in Group B. Shrestha et al. showed in their study that the mean $( \pm \mathrm{SD})$ duration of surgery was $92.8 \pm 27.82$ minutes in bupivacaine group and $88.58 \pm 25.84$ minutes in bupivacaine with midazolam group, which support the present study findings. In another study done by Sia et al found the mean $( \pm \mathrm{SD})$ duration of surgery was $78 \pm 30$ minutes in paresthesia group and $86 \pm 33$ minutes in peripheral stimulation group, which support the present study. Shrestha et al. mentioned in their study that the mean duration of surgery was $130.10 \pm 10$ minutes in Group I and 130.17 \pm 52.74 minutes in Group II, which is higher than the present study. In another study Colin et al. (2004) reported that the mean duration of surgery was $54.4 \pm 23.1$ minutes in regional anesthesia group and $62.0 \pm 24.4$ minutes in general anesthesia group, which is lesser than the present study ${ }^{13,14}$.

In this study adequate efficacy block were predominate in both groups and no significant ( $p>0.05$ ) difference was found.

Regarding the level of satisfaction of surgeon and it was found that $92.0 \%$ in Group A and $94.0 \%$ in Group B were satisfied. Patient's co-operation was found $92.0 \%$ and $94.0 \%$ in Group A and Group B respectively. No significant ( $>0.05)$ difference were found in terms of surgeon satisfaction and patients cooperation between two groups.

Regarding the complications it was found that respiratory distress was $10.0 \%$ in Group A and $4.0 \%$ in Group B in this study. Haematoma was $8.0 \%$ in Group A and $6.0 \%$ in Group B. Tourniquet pain only observed $4.0 \%$ in group B. Others complications like pneumothorax, abscess formation, hypersensitivity, CNS and CVS was not found between two groups. Significant $(\mathrm{p}<0.05)$ difference were found in terms of complications between two groups.

In this study it was observed that per-operative mean pulse rate changes at different times were almost similar between two groups no significant $(\mathrm{p}>0.05)$ mean difference was found. Similarly mean systolic blood pressure and diastolic blood pressure changes at different times were almost consistent between two groups and no significant $(p>0.05)$ difference were found. The mean $\mathrm{SPa}_{2}$ and respiratory rate changes at different times were almost regular between two groups and no significant $(\mathrm{p}>0.05)$ difference were found. Jarbo et al. (2005) found the heart rate, systolic blood pressure, diastolic blood pressure, oxygen saturation were comparable between groups 
and did not change significantly in the intraoperative or postoperative period, which is closely resemble with the present study. In another study showed stable hemodynamics parameters in their study groups, which support the present study findings ${ }^{16}$.

\section{CONCLUSION}

It can be concluded that the supraclavicular subclavian perivascular technique and axillary transarterial technique with a tourniquet both are equally effective and safe method for providing brachial plexus block distal to midarm (Lower half of the arm, elbow, forearm and hand). The only exception is the mean on set time of sensory block was $11.0 \pm 2.6$ minutes and $14.3 \pm 2.1$ minutes in Group A and Group B respectively. The mean on set time of motor block were $18.3 \pm 3.9$ minutes in Group A and 21.4 \pm 3.2 minutes in Group B. So the mean on set time of sensory block and motor block were statistically significant $(\mathrm{p}<0.05)$.

\section{DISCLOSURE}

All the authors declared no competing interest.

\section{REFERENCES}

1. Morgan EG Jr, Mikhail MS, Muray MJ, Clinical Anaesthesiology. 2005; 4:324-356.

2. Healy EJ, Knight Paul R. In: Wyle \& Churchill-Davidson. "Brachial Plexus Nerve Block"- A Practice of Anaesthesia. 2003; 7:599-628

3. Brand L. and Papper EM. "A comparison of supraclavicular and axillary technique of brachial plexus block". Anaesthesiology. 1961;22:226-229.

4. Fleck JW, Moorthy SS, Daniel J and Dierdorf SF. 1994."Brachial plexus block: a comparison of the supraclavicular lateral paravascular and axillary approaches".Reg Anesth. 1994;19:14-17.

5. Raj PP. approaches to brachial plexus anesthesia. Techniques in Regional Anesthesia and Pain Management. 1997;1:169-177.

6. Anthony R. and Brown MB. Peripheral nerve stimulator vs. paresthesia. 2004; 27:76-82.

7. Hickey R, Hoffman J, Ramamurthy S. Transarterial techniques are not effective for subclavian perivascular block. Reg Anesth. 1990;15(5):245-249.

8. Ortells-Polo MA; García-Guiral M; García-Amigueti FJ; Carral-londris JN García- Godino T; Aguiar-Mojarro JA. 1996, Brachial plexus anesthesia: results of a modified perivascular supraclavicular technique Rev Esp Anestesiol Reanim. 1996;43(3):94-98

9. Antaa R, Kirvela O, Lahdenpera A and Nieminen S, Transarterial brachial plexus anaesthesia for hand surgery": a retrospective analysis of 346 cases. J Clin Anesth. 1994;3:189-192.

10. Shrestha BR, Maharjan SK, Shrestha S, Gautam B, Thapa PB, Joshi MR, 'Comparative study between tramadol and dexamethasone as an admixture to bupivacaine in supraclavicular brachial plexuxs block'. 2007;46(168):158-164.

11. Sasada M and Smith S, Drugs in anaesthsia and intensive care, Oxford Medical Publications, London. 1997;2:8-217.

12. Webel BJ and Horlocker TT, "Nerve Blocks", In: Miller RD, Miller's Anaesthesia, BIOS Scientifics publishers limited, USA. 2005;6(1):1-3, 1685-1718

13. Sia S, Bartoli M, Lepri A, Marchini O and Ponsecchi P. Multiple-injection axillary brachial plexus block: A comparison of two methods of nerve localization nerve stimulation versus pareshthesia".Anesth Analg. 2000;91:647-651.

14. Shrestha BR, Maharjan SK, Tabedar S, 'Supraclavicular brachial plexus block with and without dexamethasone- A comparative study', Kathmandu University Medical Journal. 2003;1:158-160.

15. Annalena Andersson, Jonas A Keson, Lars B. Dahlin. Efficacy and safety of axillary brachial plexus block for operations on the hand,Scand J Plast Reconstr Surg Hand Surg. 2006;40:225-229.

16. Dogru K, Duygulu F, Yildiz K, Kotanoglu MS, Madenoglu H, Boyaci A, 'Hemodynamic and blockade effect of high/low epinephrine dose during axillary brachial plexus blockade with lidocaine 1.5\%: A randomized, doubleblinded study', Anesth Pain Med. 2003;28(5):401-405. 